\title{
Comparative Study of Simulated Floating Inductances Using Ota in Low Pass Filter
}

\author{
Manjula V. Katageri ${ }^{1}$, M. M. Mutsaddi ${ }^{2}$, Rajeshwari S. Mathad ${ }^{3}$ \\ ${ }^{I}$ Government First Grade College, BAGALKOT, India \\ ${ }^{2,3}$ Basaveshwar Science College, BAGALKOT, India
}

\begin{abstract}
Several methods of realization of floating inductance with current conveyors, current feedback amplifier has been reported. The methods for the realization of inductance simulation with electronically tunable properties using current controlled conveyors required well matching of transistors. These devices have limited performance due to component matching. Simulation of inductance is also obtained from second generation current conveyors with excessive number of components. The simulated inductance is varied through passive elements and the approach is based on the use of current differencing buffer amplifier realized with CMOS technology and is unavailable in integrated form. Operational transconductance amplifier has an attractive feature of transconductance gain which is linearly controlled over more than 4 decades from the bias current. The OTA is a commercial low cost device and also easy to implement in monolithic integrated form. The realization of floating inductance simulation is more attractive. A commercial OTA with least number of active and passive elements exhibit an attractive method to simulate a floating inductance. A review on floating inductance using number of OTAs with resistor and single capacitor is reported in terms of searching for the best method of simulating the floating inductance in the design of low pass filter.
\end{abstract}

Key words: Floating inductance, LPF-low pass filter, OTA-Operational Transconductance Amplifier.

\section{INTRODUCTION}

Floating inductance simulation is one of the important components in active filter design, oscillators and system response compensation. Several methods for realization of the floating inductance simulation have been reported [1-16]. An approach is based on second generation of current conveyors (CCCIIs), current differing buffer amplifiers (CDBAs), current feedback amplifiers (CFAs) [1,5,6,15]. The CCCII conveyors required component matching condition which is not in the view of commercial and in tunability aspect requires excessive number of active elements. Using the dual output current conveyor, the simulated inductance is varied with passive component. The approach with CDBA and CFA realization with CMOS technology is unavailable in commercial integrated form. The economic advantage in circuit design with operational transconductance amplifier (OTA) has one of the attractive features, i.e. transconductance gain which is linearly controlled over four decades. Therefore the realization technique of the floating inductance simulation based on OTA is more attractive. In this paper a review on the technique to realize the floating inductance simulation using 5-OTA, 4OTA, 3-OTA and 2-OTA are reported and verified through software Protuse Professional 7 [ 8-13]. The validity of their values is tested in low pass filter structure explaining the agreement in values of inductance implemented in the circuit.

\section{Circuit description}

Ideally the OTA is the voltage controlled current source, which is described mathematically as:

$I_{0}=g_{m}\left(V_{1}-V_{2}\right)$

Where $I_{0}$ is output current, $g_{m}=\frac{I_{B}}{2 V_{T}}$, is transconductance gain in which $\mathrm{V}_{\mathrm{T}}$ is thermal voltage and $\mathrm{V}_{1}$ and $\mathrm{V}_{2}$ denote non inverting and inverting input voltage respectively. The circuit symbol of OTA is shown in Fig. 1.

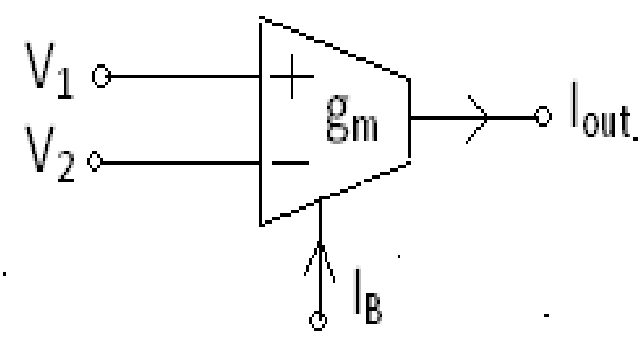

Fig. 1. 
Table 1.

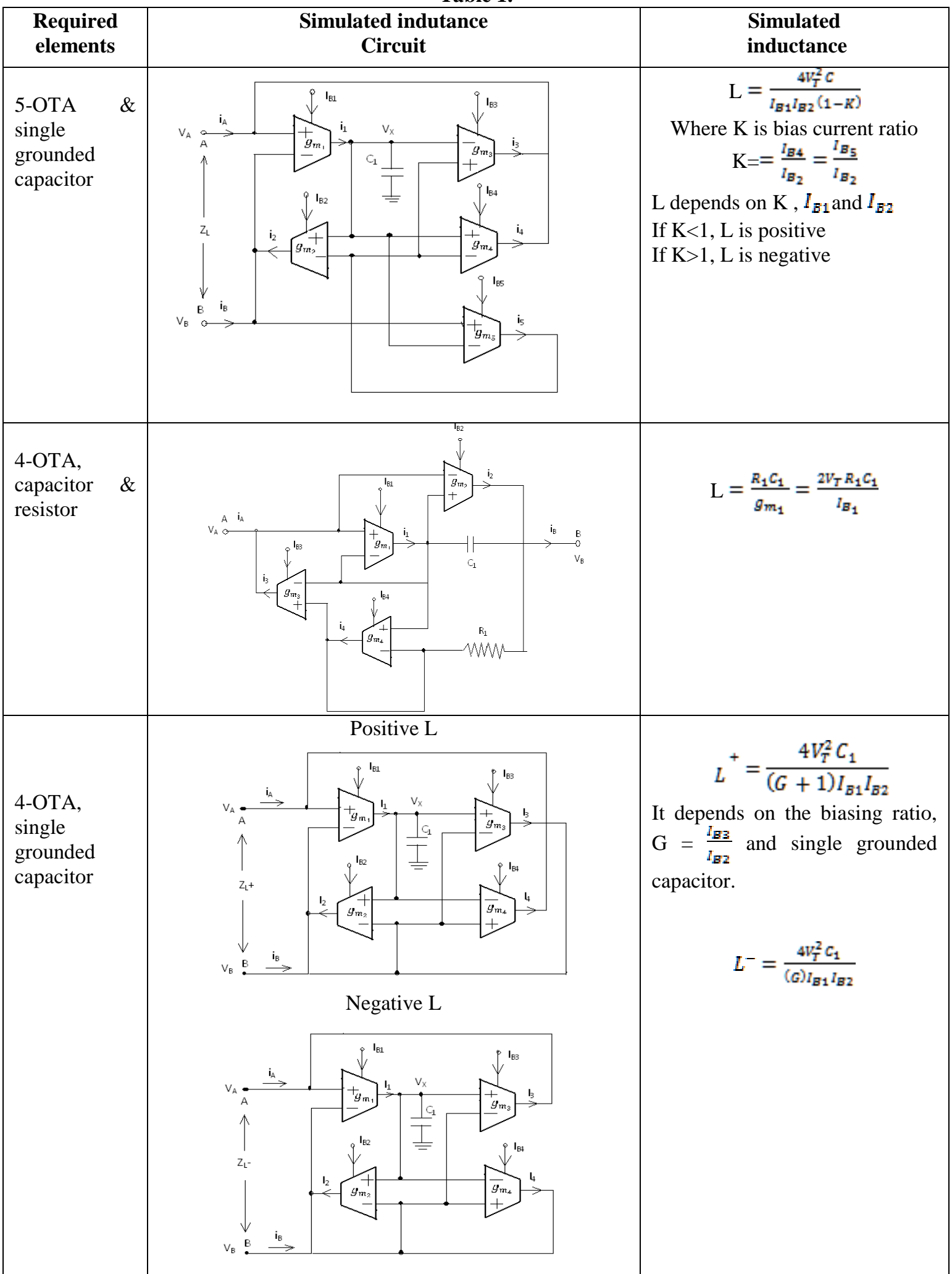




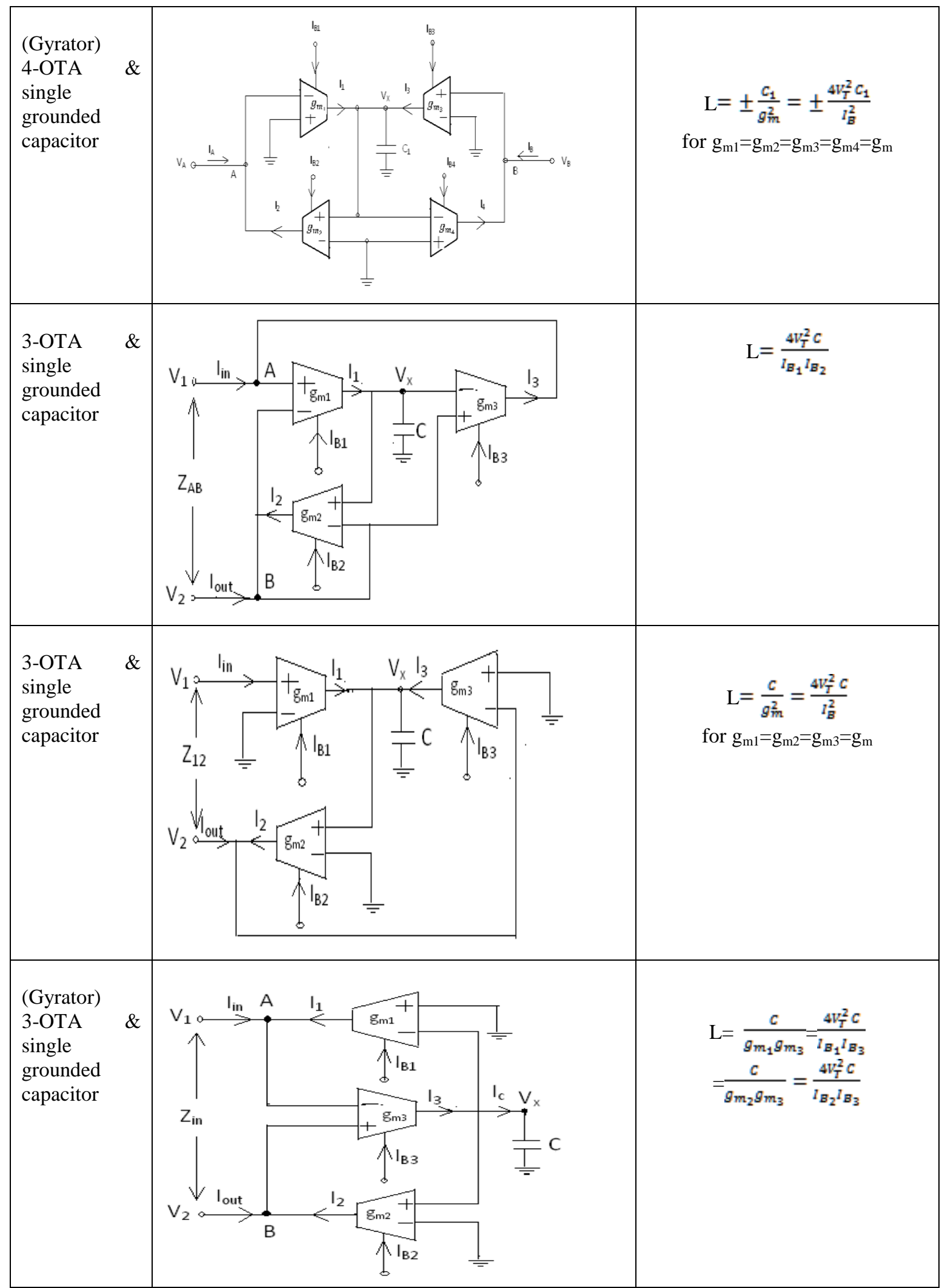

The Table 1 gives simulation circuits using 5-OTA, 4-OTA and 3-OTA with its simulated inductances. Now the simulation is possible with still minimum number of OTAs i.e. with only 2-OTAs and single grounded capacitor, is shown in Fig. 2 for both positive and negative inductances. 


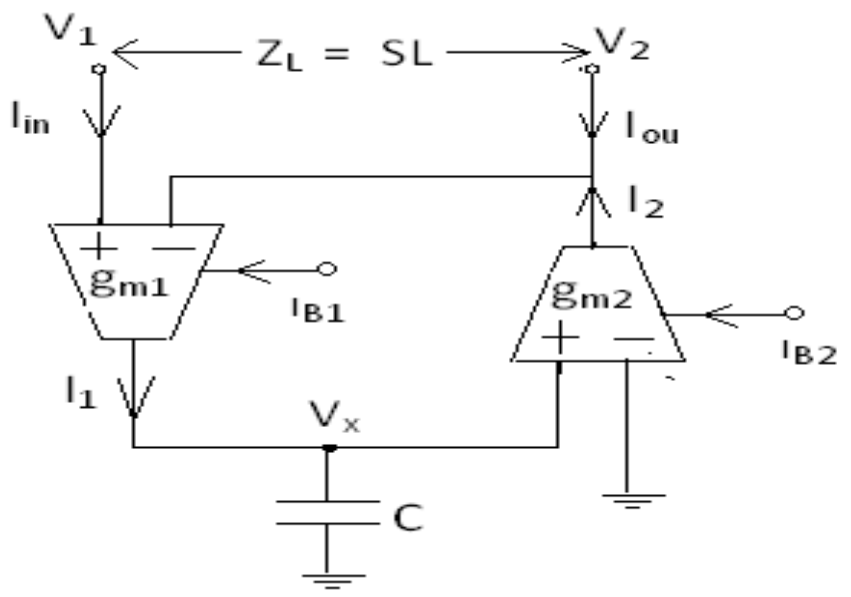

a) Positive inductance

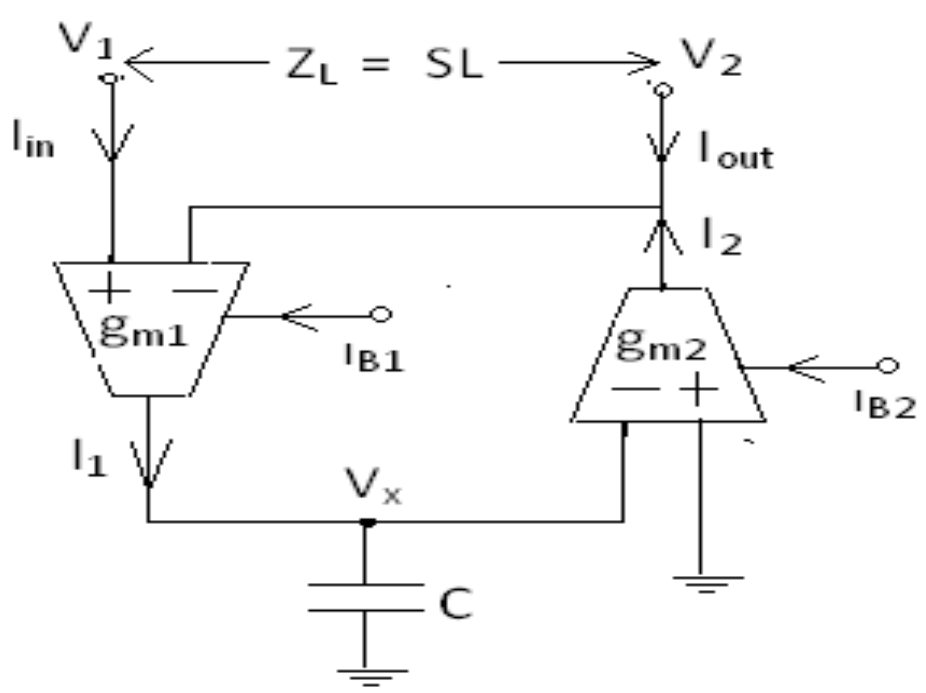

b) Negative inductance

Fig. 2

Using the property of operational transconductance amplifier, the positive floating inductance simulation is shown in Fig. 2a, the output currents of $\mathrm{OTA}_{1}$ and $\mathrm{OTA}_{2}$ are:

$l_{1}=g_{m_{1}}\left(V_{1}-V_{2}\right)$

$I_{2}=g_{m_{2}}\left(V_{X}\right)$

where $\quad V_{X}=\frac{I_{1}}{s C}=\frac{g_{m_{1}}\left(\mathbb{W}_{1}-V_{2}\right)}{s C}$

Substitute Eqn. (4) in Eqn. (3) we get,

$$
I_{2}=\frac{g_{m_{1}} g_{m_{2}}\left(\mathrm{~V}_{1}-V_{2}\right)}{s c}
$$

This gives the input impedance as:

$Z_{\text {in }}=\frac{\left(\mathbb{V}_{1}-V_{2}\right)}{I_{2}}=\frac{S C}{g_{m_{1}} g_{m_{2}}}=Z_{L}=S L$

So it is evident that the input impedance contains the inductance property as:

$L=\frac{c}{g_{m_{1}} g_{m_{2}}}$

Thus the resulting positive inductance can be electronically varied by tuning the external bias current $\mathrm{I}_{\mathrm{B} 1}$ or $\mathrm{I}_{\mathrm{B} 2}$. This positive inductance simulation $(+\mathrm{L})$ can also occur if input terminal and output feedback is connected to negative terminal of OTA's.

In the same circuit the negative floating inductance can be simulated with the circuit shown in Fig. $2 b$. The input terminal and output feedback terminals are connected with apposite polarities to obtain negative inductance.

\section{Experimental results}


The experimental arrangement of passive low pass filter shown in Fig 3. Using all types of simulated floating inductances LPF is studied by replacing passive inductor with active inductors, which is verified by Proteus Professional 7 Software. The limitation of simulation is discussed in search of best simulation circuit for floating inductance.

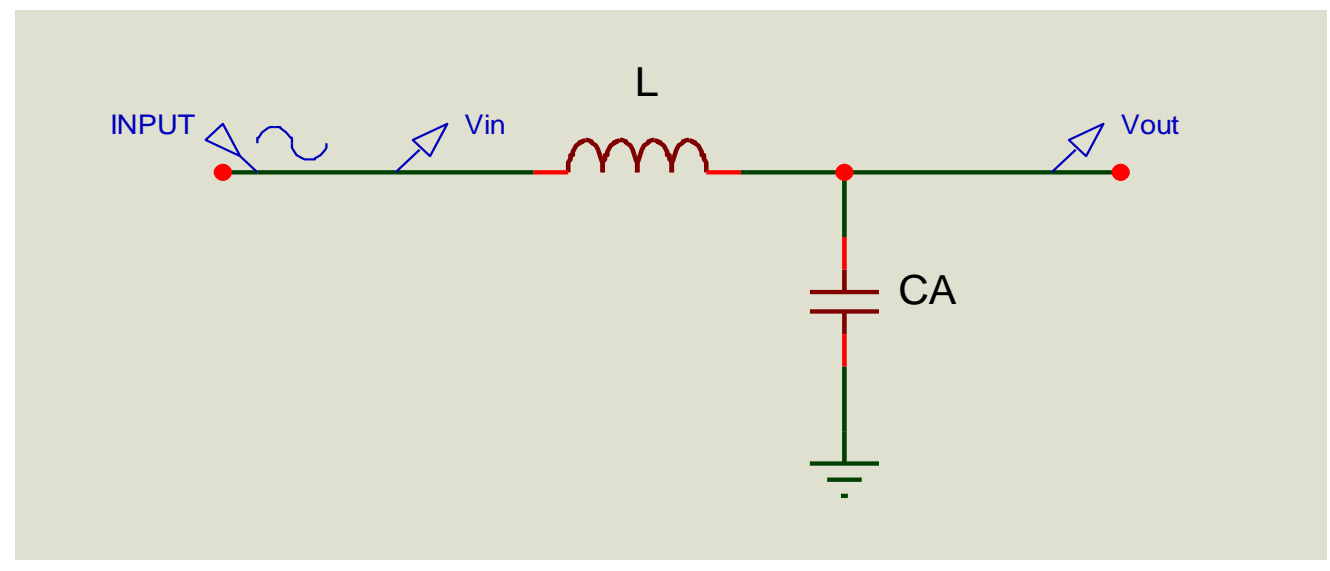

Fig.3

The simulated floating inductance is verified in low pass filter with filter capacitor $\mathrm{C}_{\mathrm{A}}=1 \mathrm{nF}$ for all bias currents from $1 \mu \mathrm{A}$ to $2000 \mu \mathrm{A}$ of LM13600 OTA. The corresponding inductances are getting from $2.712 \mathrm{H}$ to $0.678 \mu \mathrm{H}$ respectively at $\mathrm{C} 1=1 \mathrm{nf}$, which is verified in second order low pass filter, at cutoff frequency, $\mathrm{f}_{0}=$ $\frac{1}{2 \pi \sqrt{L C}}$. The cutoff frequency response curves for all types of simulated inductance circuits are studied and are given in Table 2.

In 5-OTA low pass filter simulation circuit it has good response for positive floating inductance at $\mathrm{K}<1$. The cut off frequencies matches with theoretical values with $20 \%$ error. If $\mathrm{K}>1$ for negative floating inductance the gain reduces to $-200 \mathrm{~dB}$ and fails to pass the frequency below the cut off frequency.

In 4-OTA with a resistor and single capacitor simulation circuit of low pass response the cut off frequencies does not matches with theoretical values and the low pass response is observed only above 500 $\mu \mathrm{A}$ of biasing current with ripples. In another 4-OTA with only single grounded capacitor for both positive and negative inductor low pass filter, the positive floating inductor shows an exact matching of $-3 \mathrm{~dB}$ frequencies for biasing currents $1 \mu \mathrm{A}$ to $1000 \mu \mathrm{A}$ with $\pm 6 \%$ error. The negative floating inductance low pass filter has frequency response without ripples, which does not match in cut off frequencies. This shows the 4-OTA simulator is unable to simulate negative inductance. The Gyrator 4-OTA low pass filter shows a good response for positive inductance for all bias currents of $1 \mu \mathrm{A}$ to $2000 \mu \mathrm{A}$ with an error of $\pm 6 \%$. In negative simulation inductance low pass responses have without ripples and shows its cut off frequencies matches with $-6 \mathrm{~dB}$ frequencies.

In 3-OTA simulated inductance circuits, the first two circuits shows the simulation occurred with $\pm 30 \%$ and $\pm 7 \%$ error respectively, which are observed through low pass filter. The ripple of the first circuit is less compared to second circuit. The third, gyrator 3-OTA circuit shows for all biasing currents form $1 \mu \mathrm{A}$ to $2000 \mu \mathrm{A}$ the cut off frequencies matches with $-6 \mathrm{~dB}$ frequencies instead of $-3 \mathrm{~dB}$ without ripples, which is similar with responses of negative inductance simulator of 4-OTA Gyrator low pass circuit.

The proposed 2-OTA floating simulated inductance circuit of low pass response shows the simulation is carried with $\pm 5 \%$ error with ripples at cutoff frequencies in positive inductance. The 2-OTA negative floating inductance also shows the same responses as 4-OTA and 3-OTA negative gyrator circuit, i.e. cut off frequencies that are matching with $-6 \mathrm{~dB}$ frequencies. This shows the Bessel's filter parameter structure.

Table 2.

\section{\begin{tabular}{l|l} 
Simulation circuit in second order LPF & Low pass freq. Response
\end{tabular}}




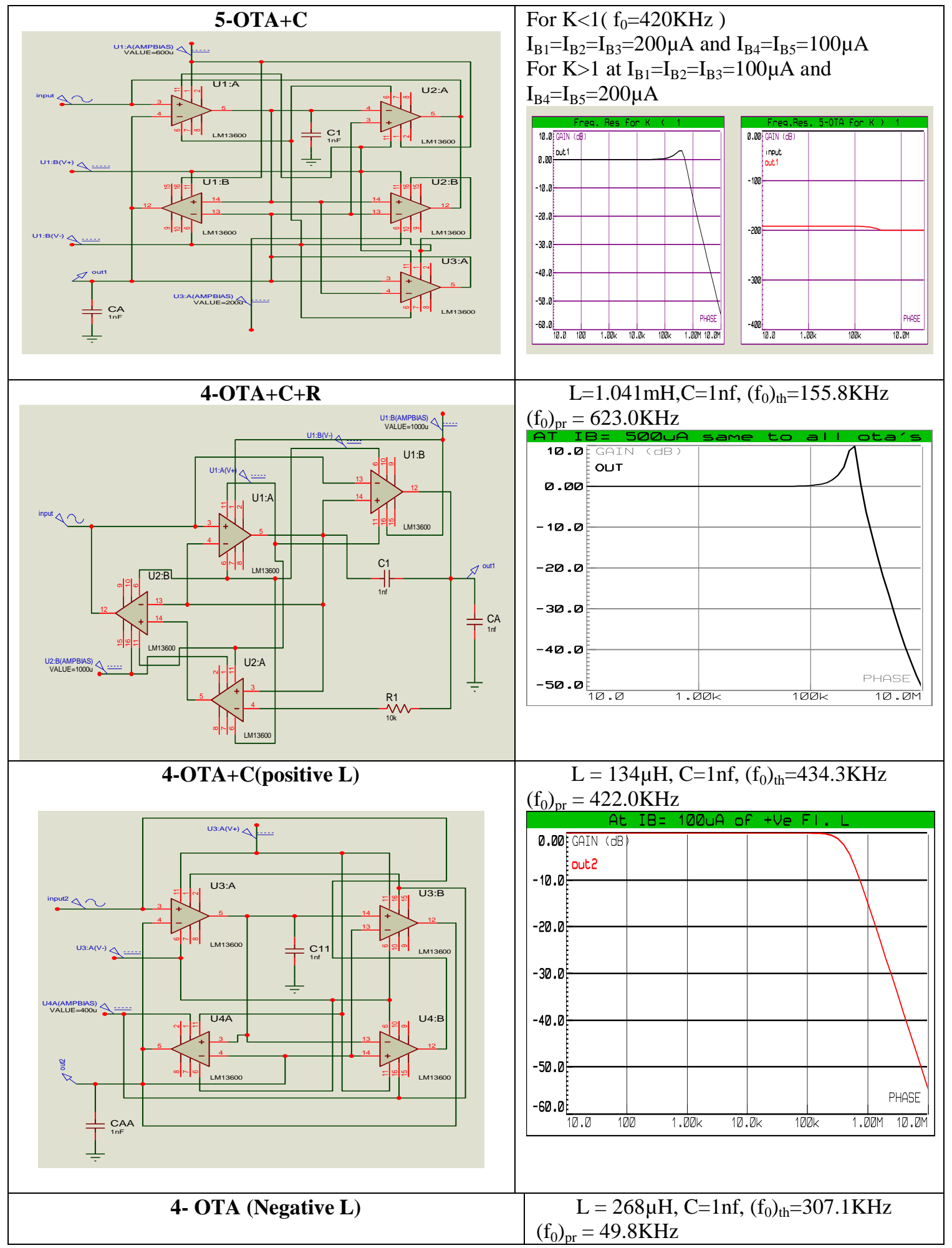




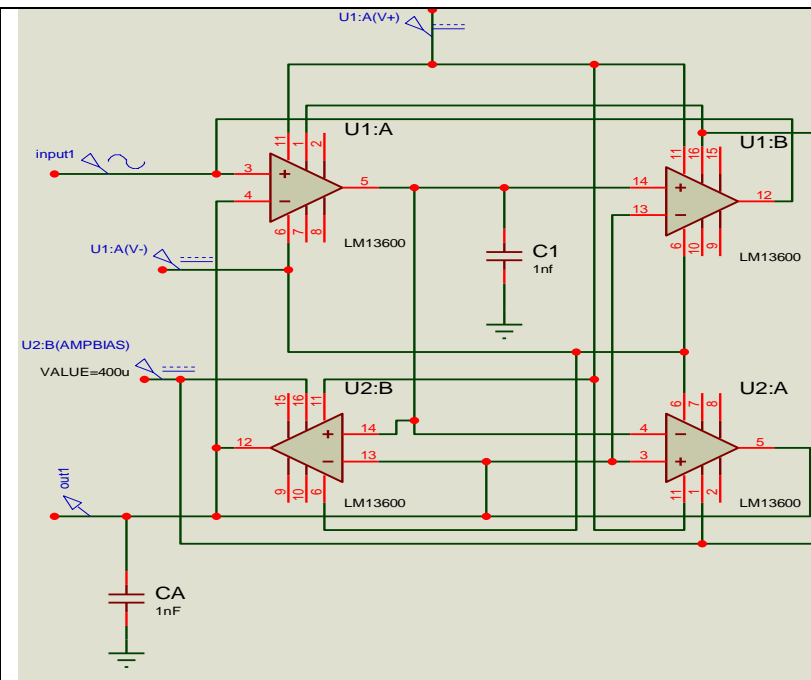

4-OTA Gyrator

For positive feedback $L$

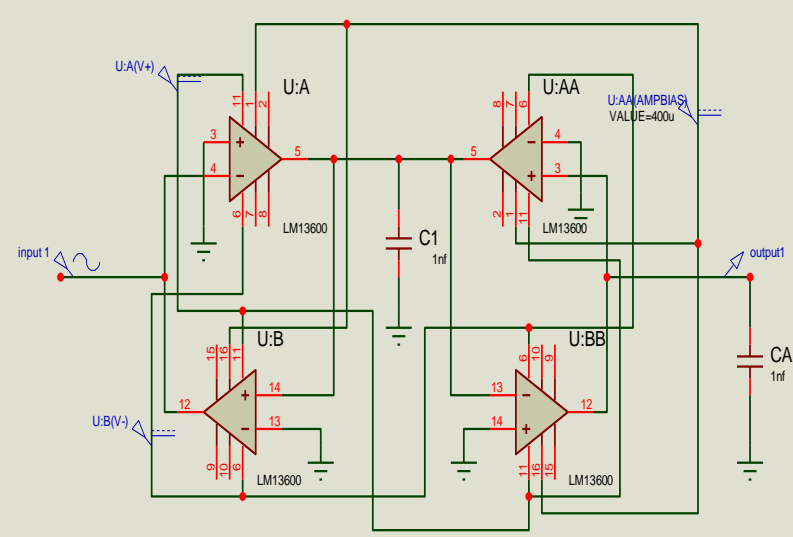

For negative feedback $L$

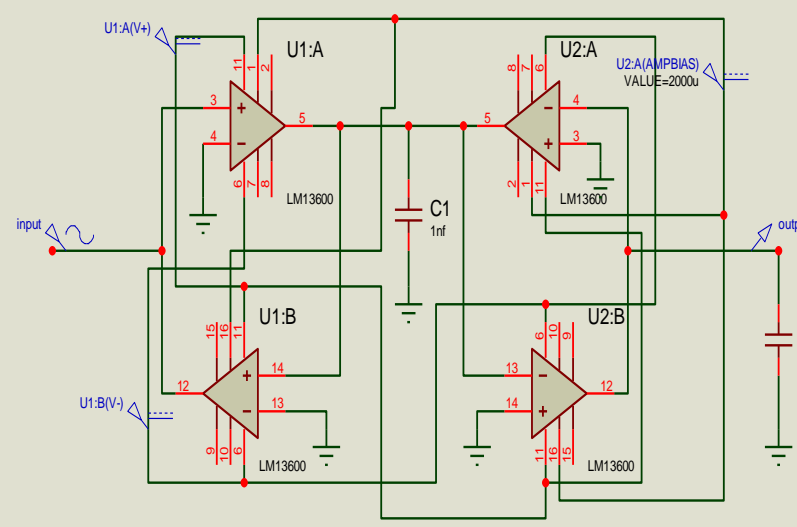

3-OTA +C

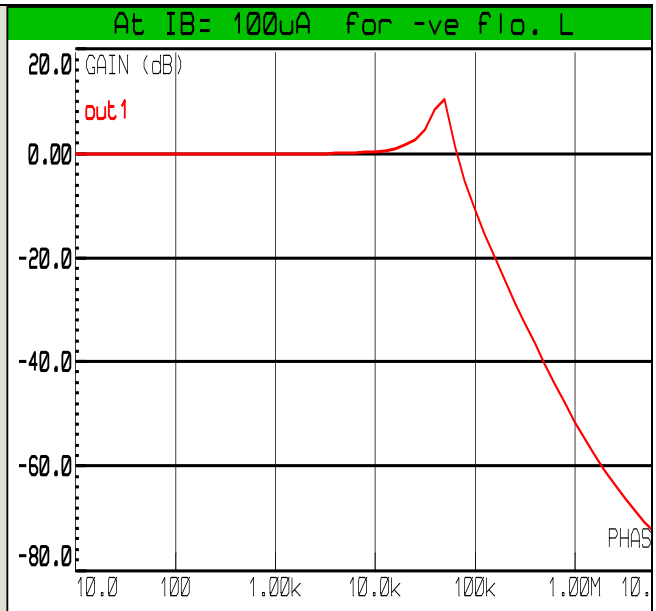

$\mathrm{L}=271.0 \mu \mathrm{H}, \mathrm{C}=1 \mathrm{nf},\left(\mathrm{f}_{0}\right)_{\mathrm{th}}=305.0 \mathrm{KHz}$ $\left(\mathrm{f}_{0}\right)_{\mathrm{pr}}=315 \mathrm{KHz}$

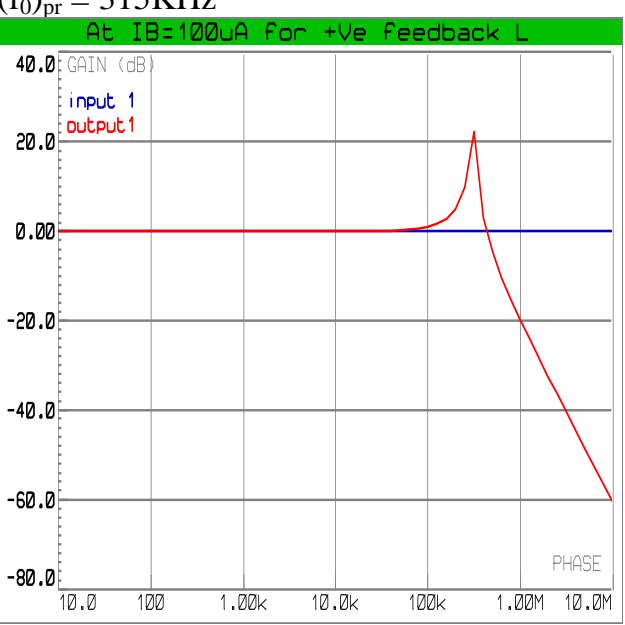

$\mathrm{L}=271.0 \mu \mathrm{H}, \mathrm{C}=1 \mathrm{nf},\left(\mathrm{f}_{0}\right)_{\mathrm{th}}=305.0 \mathrm{KHz}$ $\left(\mathrm{f}_{0}\right)_{\mathrm{pr}}=196 \mathrm{KHz}(-3 \mathrm{~dB}), 304 \mathrm{KHz}(-6 \mathrm{~dB})$

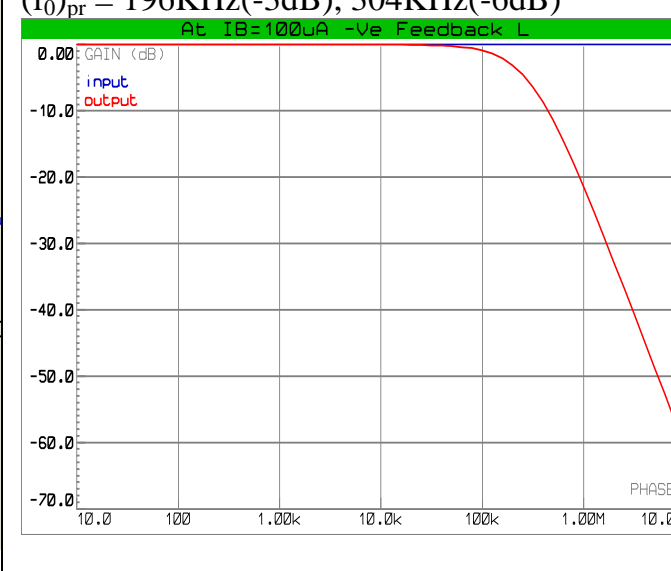

$\mathrm{L}=1.084 \mathrm{mH}, \mathrm{C}=1 \mathrm{nf},\left(\mathrm{f}_{0}\right)_{\mathrm{th}}=152.8 \mathrm{KHz}$ $\left(f_{0}\right)_{\mathrm{pr}}=192.0 \mathrm{KHz}$ 


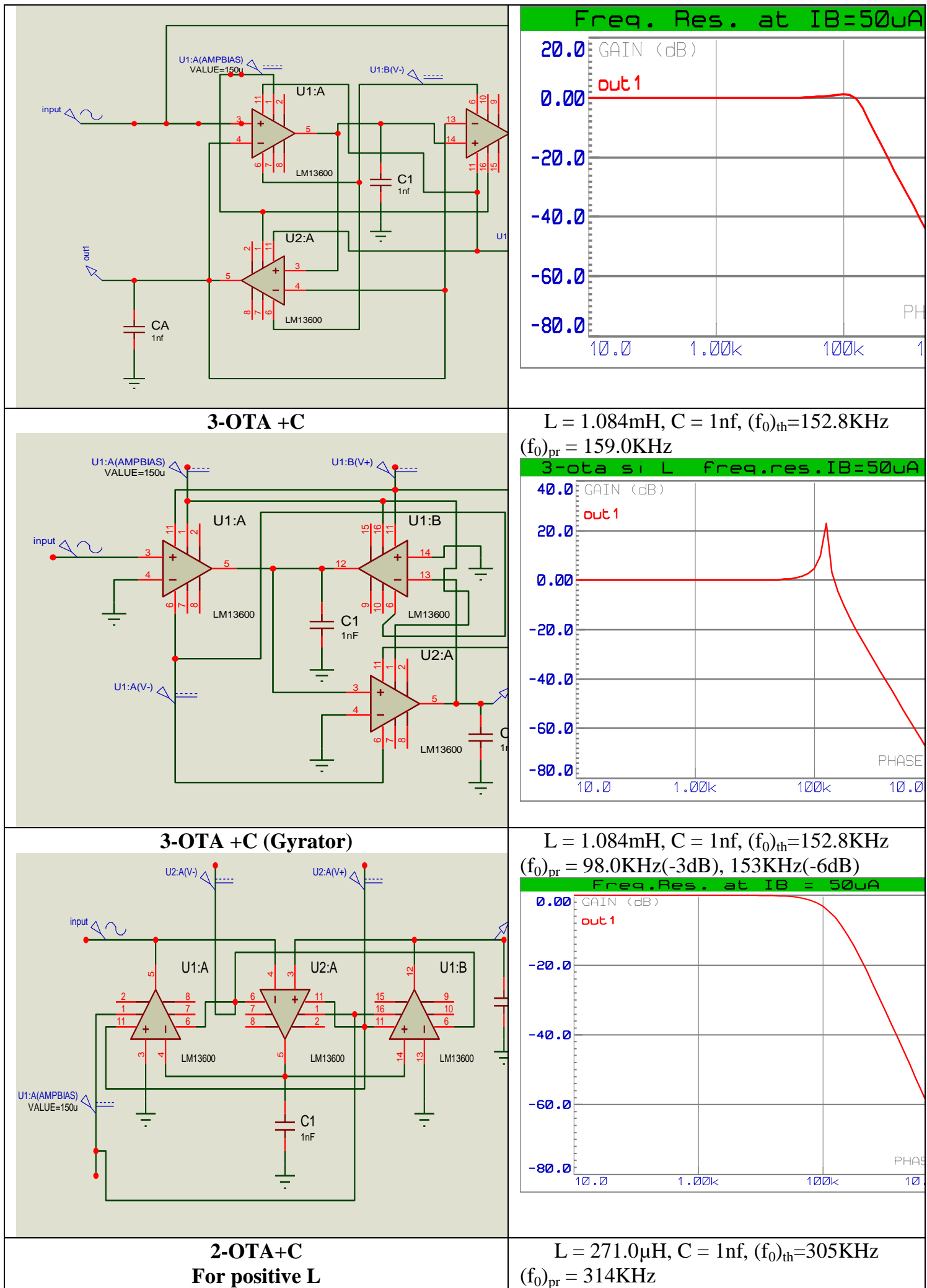




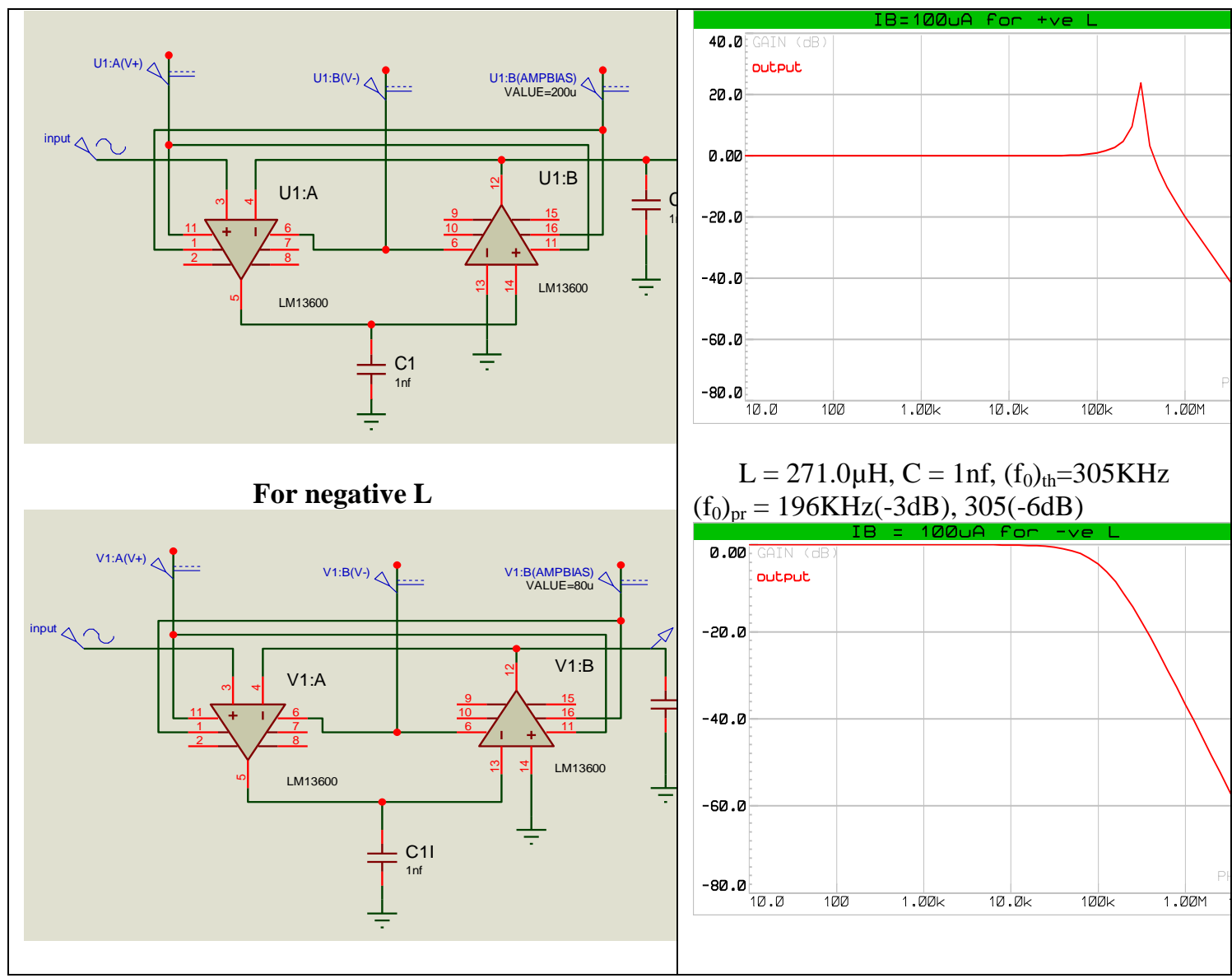

\section{CONCLUSION}

The simulation of floating inductance with less number of commercially available active devices with single grounded capacitor is one of important aspect of design in filter application. The tunable property of transconductance gain of OTA, the simulation of floating inductance with 2-OTA gives exactly matching frequencies with less error compared with 5-OTA, 4-OTA and 3-OTA low pass responses. The negative inductance simulation cut off frequencies matches with $-6 \mathrm{~dB}$ frequencies, which shows Bessel's filter characters. It is concluded that 2-OTA floating inductance simulation of positive and negative inductance is considered to be more suitable in LC ladder filter structures.

\section{ACKNOWLEDGEMENT}

Authors of the paper acknowledge the help rendered by VGST for studying the filter properties and simulation techniques under the project "Active filter design and their applications in high frequency region". We acknowledge the Principal and staff of Bharata Ratna C.N.R. Rao, research centre of BVVS Basaveshwar Science College Bagalkot

\section{REFERENCES}

[1] A.U. Keskin and E. Hangeioglu, CDBA based synthetic floating inductance circuits with electronic tuning properties, ETR J, Vol 27, No-2, 2005, 239-242

[2] Abdullah Ferikoglu, Toner Topal, Inductor Simulation With Operational Devices", G.U. Journal of Sciences, Vol. 18(1),2005,143-151

[3] Khanittha Kaewdang, K. Kumwachara and W.Surakampontorn, Electronically Tunable Floating CMOS Resistor Using OTA,IEEE ISCIT,2005, 705-708

[4] Shahram Minaei, Erkan Yuce, Oguzhan Cicekoblu, Lossless active floating inductance simulator, Third IEEE International workshop on electronic design, tests and applications, 2005

[5] H. Kuntman, M Gulsoy,O. Cicekoglu, Actively Simulated Grounded Lossy Inductors Using Third Generation Current Conveyors, Elsevier, Microelectronics Journal 31, 2000 , 245-250.

[6] P.V. Anand Mohan, Grounded Capacitor Based Grounded And Floating Inductance Simulation Using Current Conveyors, Electronics Letters, Vol. 34, 1998 , 1037-1038. 
[7] W. Kiranon and P. Pawarangkoon, Floating Inductance Simulation Based On Current Conveyors, Electronics letters, Vol. 33, No. 21, 1997, 1748- 1749

[8] Ivan S. Uzunov : Theoretical Model Of Ungrounded Inductance Realized With Two Gyrators, IEEE Transactions on circuits and systems, Vol-55,No.10 [2008], 981-985

[9] Wandee Patechmaneelumka : Simple Floating Inductance Simulators Using OTAs, IEEE, International instrumentation and measurement Technology Conference, Singapore, May 2009, 5-7

[10] Wandee Patechmaneelumka : OTAs-based Positive/Negative floating inductance simulator, International Multi Conference of Engineers and computer Scientists, Vol. II, Hong Kong, [ March 2009]

[11] Priyanka Soni, Pr.B.P.Singh, Monika Bhardwaj: Design of OTA based Floating inductor, IEEE,2011

[12] Kittisik Longsomboon, Wandee Petchmaneelumka, Thepjit Cheypoca and Vanchai Riewruja : OTAbased Electronically variable Floating inductance simulator, International Conference on Control, Automation and systems Korea, 2011,221-224

[13] Neha Gupta, Meenakhi Sutar, Sapna Singh, Priyanka Soni : Active Filter Design Using Two OTA Based Floating Inductance Simulator, International Journal of VLSI \& Single Processing Applications, Vol2,[Feb 2012], 47-50

[14] Abhishek Saini, Ankit Aswal, Ajit Singh, Flooded Cascade OTA Based $\mathrm{G}_{\mathrm{m}}-\mathrm{C}$ Filter Designing, Int.J. Of Advanced Research In Electronics And Communications Engineering (IJARECE) Vol.2, Issue 9, 2013

[15] Bhaskar, R.Senani, Raj, Simulation Of A Floating Inductance: A New Two CFOA Based Configuration" IEEE Conference 24-25,2013, 381-383 